\title{
ARTIFICIAL INTELLIGENCE HANDLING THROUgH TEACHING AND LEARNING PROCESS AND IT'S EFFECT ON SCIENCE-BASED ECONOMY
}

\author{
Mohammad ziaaddini ${ }^{1}$ and Aref Tahmasb ${ }^{2}$ \\ ${ }^{1}$ Department of Computer Engineering, shahidBahonar University, Kerman, Iran \\ ${ }^{2}$ Department of Computer Engineering, shahidBahonar University, Kerman, Iran
}

\begin{abstract}
According to this fact that educational system is the base of constant development in every country and this system educates human-forces and this forces, are accelerators and a factor, of achieving the goals of development, the educational system can play, Major role in the context economic behavior, in this context some concepts are regarded as behavioral targets and performance.In educational system, handling artificial intelligence, in teaching and learning process, had a surprising evolution through educational advantages, making job, respecting customers rights and customer relationship management, to assist priority and citizenship, correct investment through formal markets. Science-Based economy, resistible economy and a positive view to job and Iran capital,including concepts which can be institutionalize in to the educational system. In this paper it is decided to pose a new method, creating a proper cultural and scientific bed, this helps.That the educational system behavioral goals, better and stable being achieved. The method presented in this paper is general and based on handling artificial intelligence, information technology and electronic content management that means in an intelligent educational system.The educational goals can be better achieved and managed by new technology of education.
\end{abstract}

\section{KEYWORDS}

Intelligent making, electronic content, Artificial intelligence, Science-Based economy, ECM, CRM.

\section{INTRODUCTION}

Due to educational system in every country, the foundation of constant development.In Iran, special attention is paid to this issue, caused a fundamental document evolution compilation through education.In this document the process of education in all fields, including, ideological, moral, scientific, technological is presented and based on Islamic laws which is oriented to moral and ideological education. A searching education system must see all aspects needed to reach educational targets, special attention to three major elements, through teaching and learning process, means the educational system of teachers and learners is inevitable scholarly planning and science-based can achieve the behavioral targets. To extend educations and mere scientific research are not enough to raise development level, and scientific, economic development requires, evolution of economic environment through time, and science being applicable in the context of economic life, specially, in the process of globalization of trade and production. Undoubtedly to access targets as higher economic location, competinformation technologyive economy and growth, constant development needs new economy environmental conditions, understanding and paying attentionsit's needs. As planning for growth and new economy development and environment recognition and see place of Iran and recognition new sources of 
development. We can get our goals through evolution of economy, and science-based economies appearance can extend science [science of economy] as an scientific branch is a serious affair and parallel to that, the science extension theory is posed as a method for development, to present different lessons aimfully, through schools and colleges in Iran, using, information technologyand communications and handling AI in this way, can increase in the field of education, making jobs, respect customer right, and customer relationship management, to assist priority and citizenship rights, a right investment through formal markets, internal and external, science-based economy, resistible economy and also a positive view to Iran in job and capital are of concepts that can be institutionalized in education system. In this paper it is decided to establish a suitable bed for new cultural and scientific method. This method helps, better to achieve the behavioral goals of education system, especially education of Iran being stable and constant.

\section{REALIZATION OF OPERATIONAL ZONE}

Because of importance of,information technology, in 1980, and approval at high commission informatics law by revolution council. The responsibility of guidance of general informatics system of Iran was in charge of this high council.In 1990 the utility of,information technology, in the education ministry extensively installed, and gradually, benefit of this technology extended to all provinces. The lesson called; bases of computer, was added to the school programs.Of junior high school, and this book presented for all educational courses, also in colleges.During last decade, and her in electronic content management system, electronic content and electronic learning are concepts that educational system are in charge with, to pay precise scientific and functional attention to these concepts. It is an inevitable need for this country to certain information technology.

\subsection{Description of issue}

The lack of solidarity to pose electronic content in different educational units, as schools and colleges, and non-efficient traditional learning and teaching methods to achieve new educational targets are of goals determined in basic evolution document of education in Iran.The problems mentioned above are the problems which are recommended by the authors of this article:They recommend using artificial intelligence for management of posing E-content, and supervision, control as a suitable solution.

\section{BASIC CONCEPTS}

\subsection{Intelligence}

What is so special in human being or other animals that separates them from other creatures?Is such a quality only for man? Or can be seen in other animals with different degrees?From simple behavior of aunts and bees till complicated behavior of apes, determining social hierarchic order or methods to recognize multidimential patterns by pigeons. All contain degrees of intelligence. So, answer to the question that, what is intelligence, or even how is created, can help us to build up an intelligent creature, with ability to compare and acting in a real environment.One of artificial intelligence targets, is making soft ware's, which can compete with man or animal intelligence .We can use self-teaching neural networks that utilizes, correct methods just like finding real objects by human brain. Human brain capability is extra ordinary, whereas, for example if computer does better than human in the field of general information, weary very close to real artificial intelligence, computers are improving in this field.Attention some search-engines know what you are looking for in spite of that. It is possible the phrases a cultural to search, be 
much short, this is because several scientist, have taken much trouble, and created mixed complicated mathematical algorithms, which led to developed, advanced search engines. Now there are abundant closed aircuit televisions (cameras) all over, which assess all our movements. Security companies with all forces try to improve cameras understanding, because we must employ people to check monitors, and find out if there are suspicious movement, because human brain ability processing pictures better than computers.

\subsection{Artificial intelligence}

AI must be known as an open space for meeting of new and old sciences, knowledge, and technics.

The original roots and ideas of that must be searched for philosophy, linguistics, mathematics, neurology and physiology, branches and subbranches and it's different application through computer and engineering, biology, medicine communication and plenty of other fields. For better explanation of artificial intelligence, it is worthwhile to say; is it possible for man to produce an intelligence like man? Is it time for robots come in to our home, sitting with us and have a talk? Perhaps such a question can make a context to outburst of a new knowledge, called artificial intelligence.The first sparks of artificial intelligenceis from first years after Second World War. At the time that Allen Toriny 1950, posed an experience that, is machine able to compete to human's brain processes or not. The subject of artificial intelligence was presented by philosophers before electronic science appearance.Philosophers and mathematicians like Bool that posed regulations and theories about logic artificial intelligenceis a branch of computer science and is composing of three tendencies and technics, artificial neural network, fuzzy logical and evolutional algorithms are also called as four bases of soft computing sciences, which is illustrated in figure. 1

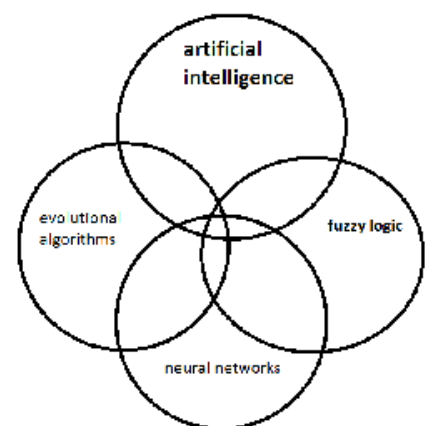

Figure 1: four pillars of soft computing

Comparing artificial intelligence with human intelligence, can say that man is able to observe and analysis subjects for the sake of judgment and taking decision, there by artificial intelligence is based on laws and regulation have prepared before on computer the aim of artificial intelligence is to bring behavior and response of a computer system to near patterns which human acts and replies. Sometimes systems design that their analysis ability is more than human. But our patterns are involved in artificial intelligence. Artificialintelligence in his short life time has been able to leap from TV games to the world of surprising subjects like expert systems of machine vision. The golden law here is that, complexity of a society is the result of complexity of it's members.(complexity-theory), so, a society with very simple elements may act intelligently and complex. 


\subsection{Intelligence}

It is not possible to have a certain definition of intelligence which is in agreement with all psychologists with different thoughts. Therefore, there are elements of intelligence which are in agree with most of researchers. Gage and Berlainer 1992 classified these elements in 3 order : 1Abilityto get through abstract affairs: That means smarter people dealing with abstract affairs ( thoughts-symbols relation, concepts, rules) until objective affairs (mechanical tools, sensational activities). 2-Ability to solve the problems, it means that, having the ability to deal with new situations, not only responses which are learned from past to known situations. 3-The ability of learning especially abstracts including existing abstracts through words and symbols and also ability to use them. Some of psychological theoricians (Karol 1963) has specified this ability as talent. Karol's definition about talent is: Amount of time which a person needs to learn a subject or acquire a skill. One of important and effective factors on intelligence, is feeding and other terms of pregnancy period. Body and mental welfare of mother and feeding properly through this period, will have important effect on baby's intelligence. Good manners of parents with infant is one of effective factors for children intelligence blooming and this is also needed for children. Intelligence blooming, proper stimulants in the living environment of a child.

\subsection{The process of learning and teaching}

To learn and teach is main problem of a knowledge-oriented society, and it's procedure to solve can be affect the future of each country. Optimum solving of teaching and learning must be done, based on dominant culture and values in the society. The model of teaching and learning must pose as suitable as with society.

Various models have presented, including Keller learning model (ARCS). Killer believes that, motivation is under effect of individual, environmental, specialties and learning materials. Killer, in his motivational, educational designing, composing theories and motivational procedures with educational designing, and forms an application resultthat causes learners to do more struggle to achieve educational goals EQ emotional model. This model emotion or feeling has much effect on learning Sam 2009. After making emotional remembrance as compare with text reports, that essential motive comes manifest the emotional model of human is, as a positive spectrum of emotions like joy, pleasure, hope and sympathy and negative spectrum consist of sadness, anger, fear disappointment and aggressiveness, emotion in the procedure of education must be in positive spectrum and preferably must be in the form of active and several of learning model which must take care to archive goals.

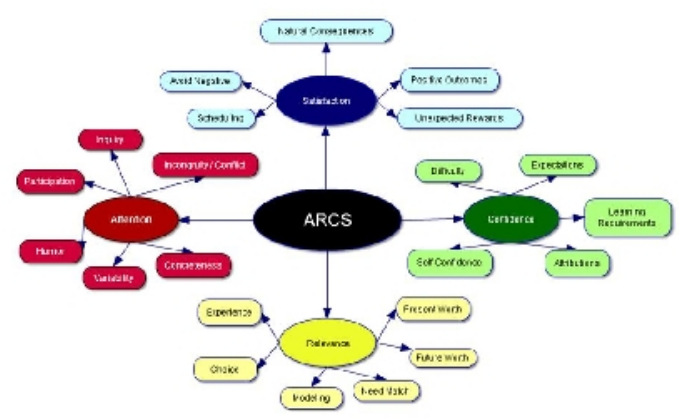

Figure2: Kellers' motivator didactic model (ARCS) 


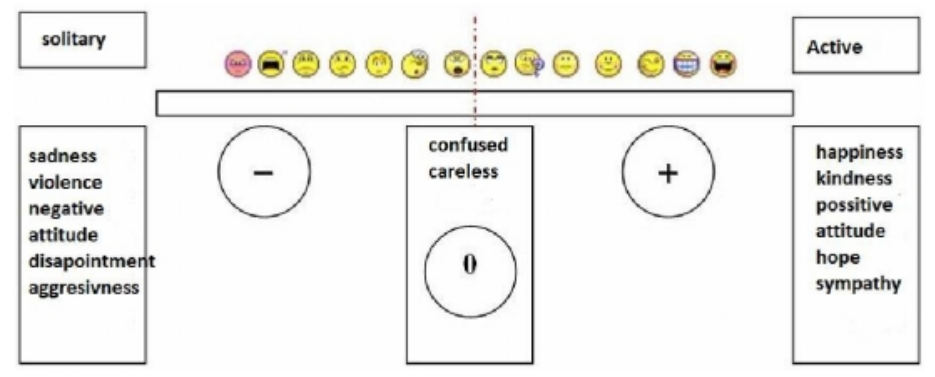

Figure 3: excitement model (EQ)

\subsection{Knowledge-Based economy}

The organization for economic co-operation and development (OECD) presents a definition for knowledge-based economy. It is an economy which directly and consistently rely on production, distribution and promotion, and using information in knowledge-based economy, instead of expensive productions with work force, production is based on science, Comparing new economic conditions with past time, shows that, the role of science through production is outstanding, so the human knowledge progress is doubled every five years and this is a cause of knowledge dealing as goods. As business is electronically and on line, some knowledgeconsuming goods, can be purchased and sold in different forms and in a figurative space in a learned-oriented economy innovation can makes plenty of income, so designing a product or goods is much more profitable than making that based on economy definition. That is a science which studies the processes of production, distribution, consuming and services or studies the welfare of man. It is also a science in relation to allocation sources, satisfying infinite needs of human being.

The science of economy in relation with production, distribution and exploitation of knowledge that answers the following questions.

- Which knowledge should be produced distributed, promoted and used?

- How much knowledge should be produced, distributed and used?

- To whom it should be produced, distributed converted and promoted?

- Who should produce, distribute, convert and promoted?

\section{SOME OF ARTIFICIAL INTELLIGENCE APPLICATIONS}

Today we can see traces of artificial intelligence in the different sciences, including medicine, air and space sciences discoveries, military weaponry, weather for casting, planning, topography and sound recognition. Hand writing recognition, word recognition, games and soft wears. There by AI experts based on different applications of this science, follow it through various branches. Artificialintelligence, in it's short period life time, could travel to a surprising world of such-elite system machine vision.

Artificial intelligence application through learning such as pilot course in an absolute figurative space, so we can use this new science with precise planning. 


\section{THE AIM OF ARTIFICIAL INTELLIGENCE}

The aim of artificial intelligence is closing the behavior and response to a computer system to patterns which man act like them and responses. Sometimes systems design that have the power to their analysis is better than man, but they use our patterns again to profit by artificial intelligence in the process of teaching and learning is essential to meet above definition.

\section{ELECTRONIC CONTENT}

E-content is a collection of contexts, photos, sonic and pictorial animations which is created for users, in other words, E-content generally applying to an informational until which, is digitally presented and can be managed electronically. This content can be presented to public as web pages, and also available as hard ware for saving information's, in the form of informational banks, videos and animations. The studies have shown, best methods of learning for people are three methods: hearing, visual and kinetic. So, E-content is the best way of teaching and in this way we must pay enough attention to cyber psychology. Paying attention to human interaction standards with computer including SCORM is useful and helps the process of teaching and learning.

\section{PROPOSED METHOD AND EDUCATIONAL UTILIZATION}

The proposed method in this paper is the electronic content oflessons is designed based on educational books content in this way, it is focused on traditional educational system which teacher is the main factor in the classroom. The content should presented as sketch in class. The main point in this method is E-content management that is important to pay special attention to content and individual differences.

\section{RESULT AND PROPOSALS}

Undoubtedly: Handling artificial intelligence through teaching and learning process is much important, of course, the quality of electronic content is of importance. By information technologyprogress, artificial intelligence is well used in various fields, including electronic trading. Considering individual differences and consumers needs is of course something common. Researches have shown that, leaving school in the electronic schools is most common than traditional schools, the main reason is how to present electronic content. It is recommend, being intelligent through education, to produce good quality electronic content a unique management for feeding educational sources which approved for each education unit, is needed learning during teaching for teachers and college professors must be planned, it is expected that, fantastic progress of information technologyin the version of web 2 in our educational system being achieved.

\section{REFERENCES}

[1] The Supreme Council of the Cultural Revolution. Supreme Council of Education. (2012)Ministry of Education. Document the fundamental transformation of education in Iran. December

[2] Hamid, Nazeman\&Alireza,Eslamifar, (2011)," Knowledge Based Economy and Sustainable Development". Knowledge and development. Vol.4, No. 33

[3] NezamAbadiPoor, Hossein. (2011) "Basic concepts of genetic algorithms and advanced topics". First edition, Kerman, martyr Bahonar University.

[4] Saif,Ali Akbar," Modern educational psychology"(2010). Seventh Edition, Tehran, era 
[5] Ebrahim Zadeh,Eessa,.(2003)" Teaching - learning and open universities and distance future”. Light Peak II

[6] Kanani,Mostafa \& EskandariAkram.”(2013)Implementation of curriculum with educational model Cl stimulation". Growth of Educational Technology, No. 7

[7] Saljoghi,Khosro.(2007), “Aqtsadmbtny science concepts and features”. Tenth Congress of the Third International Congress and cooperation in government, academia and industry.

[8] Atai ,Shervan\&RostamiNejad, Muhammad Ali,(2012),"Muslim model - Persia teaching - learning engineering". Conference on Engineering Education with a view to the future. University of Technology.

[9] Ahmad Abadi,Mohammad Reza \&KamkarPeiman, \&Zamani,Mahdi,(2012)" when. Simulation and its application in e-learning. Scientific periodical training Thssy world news". No. IV.

[10] Hariri,Mohamad. Hussein\&Mahdian,Somaieh\& Akbar Hassanzadeh. University of investigations headquarters staff in-service training on the role of human resource productivity. Isfahan University of Medical Sciences.

[11] Zandi,Bahman\&MasomiFard,Marjan\&MasomiFard,Mitra,(2012)," Educational planning in the context of e-learning systems". Quarterly training strategies.

[12] Hamid, Nazeman\& Alireza Eslamifar.(2011)." Knowledge Based Economy and Sustainable Development (design and test an analytical model of the world)".

[13] Kent L. Cyber Psychology:(2008) An Introduction To Human-Computer Interaction Cambridge University Press, New York,

[14] I. S. Jacobs \& C. P. Bean, (1963)"Fine particles, thin films and exchange anisotropy," in Magnetism, vol. III, G. T. Rado and H. Suhl, Eds. New York: Academic, pp. 271-350.

[15] Rosenberg M. (2007)'The E-Learning: Strategies for delivering knowledge in the digital age. New Jersey: Prentice Hall Publication,

\section{Authors}

Aref Tahmasb received his B.S. degree in Software Engineeringfrom the Azad University of Iran and his M.S. degree from the ShahidBahonar University of Iran. His current research interests are in the areas of pattern Recognition and data mining.He has 3 years of teaching experience incomputer.

Mohammad ziaaddini received his B.S. degree in Mathematical from the SistanBalochestan University of Iran and his M.S. degree from the Shahid BahonarUniversityof Iran. His current research interests are in the areas of network and data mining.He has 30 years of teaching experience in mathematics and computer.
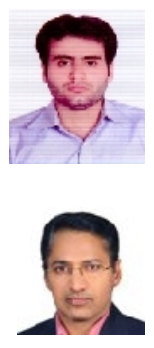